\title{
Hubungan Faktor Predisposisi terhadap Kepatuhan Ibu Hamil dalam Mengkonsumsi Tablet Besi dan Kadar Hemoglobin di Puskesmas Mangli Kabupaten Jember
}

\author{
Anindya Nur Indri $\mathbf{O}^{\mathbf{1}}$, Agustina Endah $\mathbf{W}^{\mathbf{1}}$., Dahlia I. Amareta ${ }^{\mathbf{1}}$ \\ Jurusan Kesehatan, Politeknik Negeri Jember, Indonesial \\ e-mail: anindya.oktavia11@gmail.com
}

\begin{abstract}
Anemia is a reduced levels of Hemoglobin $(\mathrm{Hb})$ in the blood. Anemia is one of the most common disorder that occurs during pregnancy, with the condition of $\mathrm{Hb}$ levels below $11 \mathrm{gr} \%$ Supplementation iron or granting tablet. Fe is an attempt important in prevent and handle Anemia, especially iron deficiency Anemia. Compliance consume iron tablets in measuring instrument from accuracy of the total tablets which was consumed, the accuracy of consuming manner iron tablets, the frequency of consumption each day. To identify relations factors predisposing, compliance in consum iron tablet and levels hemoglobin of pregnant mothers in Puskesmas Mangli Kabupaten Jember. The study ofobservation analytic. Research instruments to collect database by giving questionnaire and examination levels hemoglobin. Subjekts are 32 pregnant women. Analysis using spearmen correlation rank showed the relationship between age to compliance mother in consume iron tablet $(p=0,015)$, there was a correlation between mothers education pregnant with compliance pregnant mothers in consume iron tablet $(p=0,001)$, there was a correlation between knowledge pregnant mothers with compliance pregnant mothers in consume iron tablet $(p=0,001)$, there was a correlation between a pregnant mothers with compliance pregnant mothers in consume iron tablet ( $p=$ 0,003), there was a correlation between compliance pregnant mothers in consume iron tableton the hemoglobin pregnant mothers $(p=0,000)$. The most dominant factor which affect the compliancy consumingiron tablet during the pregnancy was pregnant mother's attitude with the score odds ratio (OR) 4,328. There was a connection between the predisposing with compliance pregnantmothersin consume iron tablet and there wasa link between compliance in consume iron tabletto the pregnant mother's hemoglobin and the most predisposition dominant factor which affect the compliancy consumingiron tablet during the pregnancy was pregnant mother's attitude.
\end{abstract}

Keywords: anemic levels, compliance, factors predisposing, hemoglobin, Iron tablet

\section{Pendahuluan}

Salah satu faktor penyebab tidak langsung kematian ibu adalah anemia. Anemia defisiensi zat besi merupakan penyebab utama anemia pada ibu hamil dibandingkan dengan defisiensi zat gizi lain, sehingga anemia gizi pada masa kehamilan sering diidentikkan dengan anemia gizi besi (Asrina dkk., 2014). Anemia merupakan keadaan di mana 
eritrosit atau hemoglobin yang beredar tidak mampu memenuhi fungsinya untuk menyediakan oksigen bagi jaringan tubuh.

Terjadinya anemia disebabkan turunnya hemoglobin di bawah nilai terendah. Pada darah orang normal mengandung 13-16 g hemoglobin ( $\mathrm{Hb}) / 100 \mathrm{cc}$ (13-16 g\%). Hemoglobin ada dalam eritrosit, maka apabila konsentrasi $\mathrm{Hb}$ turun di bawah nilai normal, akan menimbulkan anemia. Ibu hamil dikatakan anemia jika kadar $\mathrm{Hb}<11 \mathrm{~g} / \mathrm{dL}$.

Anemia defisiensi besi (ADB) masih menjadi masalah kesehatan masyarakat sehubungan dengan prevalensinya yang tinggi dan dampaknya terhadap kesehatan ibu dan bayinya. Prevalensi pada anak balita sebesar $28,1 \%$, anak 5-12 tahun 29\%, ibu hamil $37,1 \%$, remaja putri $13-18$ tahun dan wanita usia subur 15-49 tahun masing-masing sebesar 22,7\% (Naga, 2013).

Anemia pada masa kehamilan dapat menyebabkan perdarahan sebelum ataupun sesudah persalinan, meningkatkan risiko melahirkan Bayi dengan Berat Bayi Lahir Rendah $(<2,5 \mathrm{~kg})$ dan pada anemia berat bahkan dapat menyebabkan kematian ibu dan bayinya.

Diperkirakan ada 14 juta kasus perdarahan dalam kehamilan setiap tahunnya yang mana penyebab tertingginya yaitu anemia paling sedikit 128.000 perempuan mengalami perdarahan sampai meninggal (Afriyanti, 2012).

Menurut Proverawati
(2011), Penyebab paling umum dari anemia pada kehamilan adalah kurangnya pengetahuan tentang kebutuhan gizi yang menyebabkan ibu hamil menderita anemia kekurangan zat besi. Hal ini penting dilakukan pemeriksaan untuk anemia pada kunjungan pertama kehamilan. Bahkan jika tidak mengalami anemia pada saat kunjungan pertama, masih mungkin terjadi anemia pada kehamilan selanjutnya.

Frekuensi ibu hamil dengan anemia di Indonesia masih relatif tinggi yaitu $63,5 \%$. Kekurangan gizi dan perhatian yang kurang terhadap ibu hamil merupakan presdiposisi anemia defisiensi ibu hamil di Indonesia. Data proporsi anemia pada ibu hamil menurut tempat tinggal, proporsi kejadian anemia pada ibu hamil di Indonesia sebesar 37,1\%, di daerah perkotaan ibu hamil yang mengalami anemia sebanyak $36,4 \%$, dan di daerah pedesaan proporsinya sebanyak $37,8 \%$ (Riskesdas, 2013).

Upaya penanggulangan anemia defisiensi besi telah dilakukan oleh pemerintah melalui program pemberian tablet zat besi pada wanita hamil, tetapi upaya tersebut belum memberikan hasil yang memuasakan.

Kebutuhan zat besi meningkat dua kali lipat dari kebutuhan sebelum hamil. 


\section{ISSN : 2354-5852 \\ e-ISSN : 2579-5783}

Suplementasi besi atau pemberian tablet besi (Fe) merupakan salah satu upaya penting dalam mencegah dan menanggulangi anemia, khususnya anemia kekurangan besi.

Kepatuhan dalam mengkonsumsi tablet besi adalah ketaatan ibu hamil melaksanakan anjuran petugas kesehatan untuk mengkonsumsi tablet zat besi. Kepatuhan mengkonsumsi tablet zat besi diukur dari ketepatan jumlah tablet yang dikonsumsi, ketepatan cara mengkonsumsi tablet zat besi, frekuensi konsumsi perhari.

Hasil Riskesdas 2010, menunjukkan bahwa $80,7 \%$ perempuan usia 10-59 tahun yang hamil mendapat atau membeli tablet $\mathrm{Fe}$ dengan jumlah hari minum tabel besi. Konsisten ibu hamil yang tinggal diperdesaan $24,8 \%$ selalu lebih tinggi di banding ibu yang tinggal di perkotaan $14,1 \%$ yang tidak minum tablet besi $(\mathrm{Fe})$ untuk mencegah anemia.

Berdasarkan laporan Dinas Kesehatan Kabupaten Jember tahun 2015, prevalensi anemia pada ibu hamil paling tinggi adalah di wilayah kerja Puskesmas Mangli, dari 1489 ibu hamil $48,67 \%$ mengalami anemia. Data hasil survei di Puskesmas Mangli pada bulan Januari-Juli 2016, jumlah ibu hamil yang datang memeriksakan kehamilan dan diperiksa kadar $\mathrm{Hb}$ nya diketahui 98 ibu hamil.
Penelitian ini bertujuan
untuk menganalisis
faktor predisposisi, kepatuhan dalam mengkonsumsi tablet $\mathrm{Fe}$ dan kadar hemoglobin ibu hamil, karena faktor predisposisi merupakan faktor yang mempermudah perubahan perilaku yang didasari oleh pemikiran atau motivasi untuk berperilakudan kejadian anemia masih tetap menjadi masalah dunia khususnya di negara-negara berkembang dan belum mencapai target yang diinginkan, meskipun setiap tahunnya mengalami penurunan dan anemia juga dapat mempengaruhi status gizi ibu hamil.

\section{Metode}

Penelitian ini merupakan penelitian observasional analitik. Penelitian dilakukan di Puskesmas Mangli Kabupaten Jember. Waktu penelitian pada bulan Juni-Juli 2016.

Variabel penelitian yaitu meliputi Variabel Independen (bebas): Faktor Predisposisi antara lain umur ibu, pendidikan, pekerjaan, pengetahuan, dan sikap; variabel antara, yaitu kepatuhan ibu hamil dalam mengkonsumsi tablet besi; dan variabel dependen (terikat), yaitu kadar hemoglobin ibu hamil.

\subsection{Metode Pengumpulan Data}

Populasi pada penelitian ini adalah ibu hamil anemia yang mengunjungi Puskesmas Mangli 
kabupaten Jember sebanyak 98 orang pada bulan Januari - Juli 2016. Jumlah sampel 32 subjek yang diambil dengan metode simple random sampling, dengan kriteria inklusi: Ibu hamil trimester II dan III yang bertempat tinggal di wilayah kerja puskesmas Mangli, ibu hamil yang mendapatkan tablet Fe, subjek bersedia untuk mengikuti penelitian dan telah menandatangani informed consent. Kriteria eksklusi yang dilakukan meliputi: pindah wilayah kerja, pindah rumah. Instrumen yang digunakan dalam penelitian ini adalah kuesioner dan alat pengukur kadar hemoglobin.

\subsection{Metode Analisis Data}

Analisis data dilakukan melalui univariat, bivariat dengan uji Spearman Rank, dan analisis multivariat dengan analisis regresi logistik taraf signifikan atau batas kepercayaan $95 \%(0,05)$. variabel dependen.

\section{Hasil dan Pembahasan}

Karakteristik subjek dibagi menjadi karakteristik subjek menurut umur, pendidikan, pekerjaan, pengetahuan, sikap, Kadar $\mathrm{Hb}$, kepatuhan ibu hamil yang disajikan pada Tabel 1 berikut.

Tabel 1. Distribusi Frekuensi Karakteristik Subjek

\begin{tabular}{lcc}
\hline Variabel & n & $\mathbf{( \% )}$ \\
\hline Umur & & \\
$<21$ & 10 & 31,25 \\
$21-35$ & 18 & 56,25 \\
$>35$ & 4 & 12,5 \\
\hline
\end{tabular}

Tingkat Pendidikan

\begin{tabular}{lcc}
\hline SD & 5 & 15,6 \\
\hline SMP & 15 & 46,9 \\
\hline SMA/SMK & 10 & 31,25 \\
\hline SARJANA & 2 & 6,25 \\
\hline Pekerjaan & & \\
\hline $\begin{array}{l}\text { Tidak } \\
\text { Bekerja }\end{array}$ & 28 & 87,5 \\
\hline Bekerja & 4 & 12,5 \\
\hline Pengetahuan & & \\
\hline Kurang & 15 & 46,9 \\
\hline Sedang & 15 & 46,9 \\
\hline Baik & 2 & 6,25 \\
\hline Sikap & & \\
\hline Kurang & 12 & 37,5 \\
\hline Sedang & 11 & 34,4 \\
\hline Baik & 9 & 28 \\
\hline Kepatuhan & & \\
\hline $\begin{array}{l}\text { Tidak } \\
\text { Patuh }\end{array}$ & 19 & 59,4 \\
\hline Patuh & 13 & 40,6 \\
\hline Kadar & & \\
Hemoglobin & & 59,4 \\
\hline Rendah & 19 & 40,6 \\
\hline Normal & 13 & 100 \\
\hline Jumlah & 32 & \\
\hline & & \\
\hline
\end{tabular}

Tabel 1, karakteristik subjek berdasarkan umur, ibu hamil memiliki rata-rata umur antara 2035 tahun yaitu sebanyak 18 subjek dengan persentase 56,25\%. Umur ibu hamil 21-35 merupakan umur produktif. Tingkat pendidikan subjek menunjukkan jumlah ibu hamil paling besar pendidikannya SMP sebesar $46,9 \%$ yaitu sebanyak 15 subjek. Subjek yang tidak bekerja lebih banyak dibandingkan dengan subjek yang bekerja. Rata-rata berprofesi sebagai ibu rumah tangga.

Pengetahuan ibu merupakan hal-hal yang diketahui dan 
dipahami oleh ibu mengenai gizi dan anemia. Hanya 6,25\% ibu hamil yang memiliki tingkat pengetahuan baik. Sebagian besar ibu hamil memiliki sikap yang kurang dalam mengkonsumsi tablet $\mathrm{Fe}$ yaitu $37,5 \%$ sebayak 12 ibu hamil. Ibu hamil yang tergolong tidak patuh sebesar $59,4 \%$. Kepatuhan mengkonsumsi tablet zat besi di ukur dari ketepatan jumlah tablet yang dikonsumsi, ketepatan cara mengkonsumsi tablet zat besi, frekuensi konsumsi perhari. Berdasarkan tabel 1 diketahui bahwa lebih dari $50 \%$ ibu hamil tergolong tidak patuh yaitu sebanyak 19 subjek dengan persentase $\quad 59,4 \%$. Kadar hemoglobin ibu hamil diperiksa menggunakan metode sahli, menunjukkan bahwa sebagian besar ibu hamil mengalami anemia dengan persentase sebesar $54,9 \%$ dan jumlah subjek 19 ibu hamil. Sedangkan ibu hamil yang memiliki kadar hemoglobin normal atau tergolong kedalam kategori ibu hamil yang tidak mengalami anemia sebesar 40,6 \% dengan jumlah subjek 13 ibu hamil.

Umur reproduksi yang optimal bagi ibu hamil adalah antara 20-30 tahun, karena rahim dan bagian tubuh lainnya sudah siap untuk menerima kehamilan. Berikut hasilnya dapat dilihat pada tabel 2.

Tabel 2. Hasil Uji Korelasi Spearman Rank Umur terhadap Kepatuhan Ibu Hamil dalam Mengkonsumsi Tablet Besi $(\mathrm{Fe})$

\begin{tabular}{|c|c|c|c|c|c|c|c|c|}
\hline \multirow{3}{*}{ Umur (tahun) } & \multicolumn{4}{|c|}{ Kepatuhan } & \multirow{2}{*}{\multicolumn{2}{|c|}{ Total }} & \multirow{3}{*}{ p Value } & \multirow{3}{*}{$r$} \\
\hline & \multicolumn{2}{|c|}{ Tdk Patuh } & \multicolumn{2}{|c|}{ Patuh } & & & & \\
\hline & $\mathbf{n}$ & $\%$ & n & $\%$ & $\mathbf{N}$ & $\%$ & & \\
\hline$<21$ & 8 & 80 & 2 & 20 & 10 & 31,25 & \multirow{4}{*}{0,015} & \multirow{4}{*}{$\begin{array}{c}0,42 \\
6\end{array}$} \\
\hline $21-35$ & 11 & 61 & 7 & 38,9 & 18 & 56,25 & & \\
\hline$>35$ & 0 & 0 & 4 & 100 & 32 & 32 & & \\
\hline \multicolumn{5}{|c|}{ Jumlah } & 32 & 100 & & \\
\hline
\end{tabular}

Tabel 3. Hasil Uji Korelasi Spearman Rank Pendidikan terhadap Kepatuhan Ibu Hamil dalam Mengkonsumsi Tablet Besi (Fe)

\begin{tabular}{|c|c|c|c|c|c|c|c|c|}
\hline \multirow{3}{*}{ Pendidikan } & \multicolumn{4}{|c|}{ Kepatuhan } & \multirow{2}{*}{\multicolumn{2}{|c|}{ Total }} & \multirow{3}{*}{$\underset{\text { Value }}{p}$} & \multirow{3}{*}{$r$} \\
\hline & \multicolumn{2}{|c|}{ Tdk Patuh } & \multicolumn{2}{|c|}{ Patuh } & & & & \\
\hline & $\mathbf{n}$ & $\%$ & $\mathrm{n}$ & $\%$ & $\mathbf{n}$ & $\%$ & & \\
\hline SD & 4 & 80 & 1 & 20 & 5 & 15,6 & & \\
\hline SMP & 14 & 93,3 & 1 & 6,7 & 15 & 46,9 & 0,001 & 0,697 \\
\hline SMA/SMK & 1 & 10 & 9 & 90 & 10 & 31,2 & & \\
\hline
\end{tabular}




\begin{tabular}{ccccccc} 
Sarjana & 0 & 0 & 2 & 100 & 2 & 6,2 \\
\hline & Jumlah & & & 32 & 100 \\
\hline
\end{tabular}

Tabel 4. Hasil Uji Korelasi Spearman Rank Pekerjaan terhadap Kepatuhan Ibu Hamil dalam Mengkonsumsi Tablet Besi (Fe)

\begin{tabular}{|c|c|c|c|c|c|c|c|c|}
\hline \multirow{3}{*}{ Pekerjaan } & \multicolumn{4}{|c|}{ Kepatuhan } & \multirow{2}{*}{\multicolumn{2}{|c|}{ Total }} & \multirow{3}{*}{$\underset{\text { Value }}{p}$} & \multirow{3}{*}{$r$} \\
\hline & \multicolumn{2}{|c|}{ Tdk Patuh } & \multicolumn{2}{|c|}{ Patuh } & & & & \\
\hline & $\mathbf{n}$ & $\%$ & n & $\%$ & $\mathbf{N}$ & $\%$ & & \\
\hline Tidak Bekerja & 19 & 67,9 & 9 & 32,1 & 28 & 87,5 & \multirow{3}{*}{0,009} & \multirow{3}{*}{0,457} \\
\hline Bekerja & 0 & 0 & 4 & 100 & 4 & 12,5 & & \\
\hline \multicolumn{5}{|c|}{ Jumlah } & 32 & 100 & & \\
\hline
\end{tabular}

Tabel 5. Hasil Uji Korelasi Spearman Rank Pengetahuan terhadap Kepatuhan Ibu Hamil dalam Mengkonsumsi Tablet Besi (Fe)

\begin{tabular}{|c|c|c|c|c|c|c|c|c|}
\hline \multirow{3}{*}{ Pengetahuan } & \multicolumn{4}{|c|}{ Kepatuhan } & \multirow{2}{*}{\multicolumn{2}{|c|}{ Total }} & \multirow{3}{*}{$\underset{\text { Value }}{p}$} & \multirow{3}{*}{$r$} \\
\hline & \multicolumn{2}{|c|}{ Tdk Patuh } & \multicolumn{2}{|c|}{ Patuh } & & & & \\
\hline & $\mathbf{n}$ & $\%$ & n & $\%$ & $\mathbf{N}$ & $\%$ & & \\
\hline Kurang & 13 & 86,7 & 2 & 13,3 & 15 & 46,9 & \multirow{4}{*}{0,001} & \multirow{4}{*}{0,553} \\
\hline Sedang & 6 & 40 & 9 & 60 & 15 & 46,9 & & \\
\hline Baik & 0 & 0 & 2 & 100 & 2 & 6,2 & & \\
\hline \multicolumn{5}{|c|}{ Jumlah } & 32 & 100 & & \\
\hline
\end{tabular}

Tabel 6. Hasil Uji Korelasi Spearman Rank Sikap Ibu terhadap Kepatuhan Ibu Hamil dalam Mengkonsumsi Tablet Besi (Fe)

\begin{tabular}{|c|c|c|c|c|c|c|c|c|}
\hline \multirow{3}{*}{ Sikap } & \multicolumn{4}{|c|}{ Kepatuhan } & \multirow{2}{*}{\multicolumn{2}{|c|}{ Total }} & \multirow{3}{*}{$\underset{\text { Value }}{p}$} & \multirow{3}{*}{$r$} \\
\hline & \multicolumn{2}{|c|}{ Tdk Patuh } & \multicolumn{2}{|c|}{ Patuh } & & & & \\
\hline & $\mathbf{n}$ & $\%$ & $\mathbf{n}$ & $\%$ & $\mathbf{N}$ & $\%$ & & \\
\hline Kurang & 12 & 100 & 0 & 0 & 12 & 37,5 & \multirow{4}{*}{0,003} & \multirow{4}{*}{0,802} \\
\hline Sedang & 7 & 63,6 & 4 & 36,4 & 11 & 34,4 & & \\
\hline Baik & 0 & 0 & 9 & 100 & 9 & 28,1 & & \\
\hline \multicolumn{5}{|c|}{ Jumlah } & 32 & 100 & & \\
\hline
\end{tabular}

Tabel 7. Hasil Uji Korelasi Spearman Rank Kadar Hemoglobin Ibu Hamil terhadap Kepatuhan Ibu Hamil dalam Mengkonsumsi Tablet Besi (Fe)

\begin{tabular}{|c|c|c|c|c|c|c|c|c|}
\hline \multirow{3}{*}{ Kadar $\mathbf{H b}$} & \multicolumn{4}{|c|}{ Kepatuhan } & \multirow{2}{*}{\multicolumn{2}{|c|}{ Total }} & \multirow{3}{*}{$\underset{\text { Value }}{p}$} & \multirow{3}{*}{$\boldsymbol{r}$} \\
\hline & \multicolumn{2}{|c|}{ Tdk Patuh } & \multicolumn{2}{|c|}{ Patuh } & & & & \\
\hline & $\mathbf{n}$ & $\%$ & n & $\%$ & n & $\%$ & & \\
\hline Tdk Normal & 19 & 100 & 0 & 0 & 19 & 59,4 & \multirow{3}{*}{0,000} & \multirow{3}{*}{1.000} \\
\hline Normal & 0 & 0 & 13 & 100 & 13 & 40,6 & & \\
\hline \multicolumn{5}{|c|}{ Jumlah } & 32 & 100 & & \\
\hline
\end{tabular}


Berdasarkan analisis bivariat yang telah diuji statistik Korelasi Rank Spearman tentang hubungan umur, pendidikan, pekerjaan, pengetahuan; sikap ibu hamil; terhadap kepatuhan ibu hamil dalam mengkonsumsi tablet besi di peroleh nilai $\mathrm{p}=0,015$; 0,$001 ; 0,09 ; 0,01 ; 0,03$ dengan korelasi $(\alpha)<0,05$. Artinya bahwa ada hubungan umur, pendidikan, pekerjaan, pengetahuan, sikap ibu hamil terhadap kepatuhan ibu hamil dalam mengkonsumsi tablet besi.

Hasil penelitian menunjukkan bahwa ibu hamil yang tidak patuh dalam mengkonsumsi tablet besi selama kehamilan memiliki kadar hemoglobin dibawah normal atau tergolong anemia. Sebaliknya ibu hamil yang patuh dalam mengkonsumsi tablet besi selama kehamilan memiliki kadar hemoglobin normal atau tidak tergolong anemia. Hasil analisis bivariat yang telah diuji statistik Korelasi Rank Spearman tentang hubungan kepatuhan ibu hamil dalam mengkonsumsi tablet besi terhadap kadar Hemoglobin ibu hamil di peroleh nilai $\mathrm{p}=0,000$ dengan korelasi $(\alpha)<0,05$. Artinya terdapat hubungan kepatuhan ibu hamil dalam mengkonsumsi tablet besi terhadap kadar Hemoglobin ibu hamil, semakin patuh ibu hamil dalam mengkonsumsi tablet besi selama kehamilan, maka semakin kecil pula kemungkinan ibu mengalami anemia.

Tabel 8 menunjukkan hasil analisis multivariat dengan uji regresi logistik diketahui nilai odds ratio setiap variabel yang berhubungan dengan kepatuhan ibu hamil dalam mengkonsumsi tablet besi.

Tabel 8. Hasil uji regresi logistik faktor yang mempengaruhi kepatuhan ibu hamil dalam mengkonsumsi tablet besi.

\begin{tabular}{ccccc}
\hline \multirow{2}{*}{ Faktor kepatuhan } & \multirow{2}{*}{ Sig } & \multirow{2}{*}{ OR } & \multicolumn{2}{c}{ 95\% CI for OR } \\
\cline { 4 - 5 } Usia & 0,026 & 0,675 & 0,237 & 2,043 \\
Pendidikan & 0,999 & 3,867 & 1,017 & 10,994 \\
Pekerjaan & 0,779 & 0,156 & 0,378 & 2,659 \\
Pengetahuan & 0,014 & 1,750 & 0,592 & 9,695 \\
Sikap & 0,999 & 4,238 & 1,998 & 11,881 \\
Konstanta & 0,999 & 0,000 & & \\
& & & &
\end{tabular}


Hubungan Umur terhadap Kepatuhan Ibu Hamil dalam Mengkonsumsi Tablet Besi (Fe).

Pada saat penelitian dilapang diketahui ibu hamil dengan umur $<21$ cenderung tidak patuh dalam mengkonsumsi tablet besi, setelah dilakukan wawancara pada ibu hamil diketahui ibu hamil kurang dapat menyerap informasi dari petugas kesehatan tentang pentingnya mengkonsumsi tablet besi selama kehamilan. Ibu hamil yang datang rata-rata mengalami kehamilan pertama. Pengalaman yang kurang juga menyebabkan ibu hamil dengan umur yang masih muda cenderung tidak patuh, karena ibu hamil masih merasa kurang siap, kurang paham pentingnya tablet besi bagi kehamilan, dan dampak negatif yang akan ditimbulkan jika ibu hamil tidak mengkonsumsi tablet besi selama kehamilan. Selain itu juga kurangnya motivasi dan dukungan dari lingkungan sekitar seperti suami dan keluarga.

\section{Hubungan Pendidikan terhadap Kepatuhan Ibu Hamil dalam Mengkonsumsi Tablet Besi (Fe).} Tingkat pendidikan berhubungan dengan kemampuan subjek memahami informasi tentang kesehatan yang diperoleh. Semakin baik tingkat pendidikan seseorang, maka informasi kesehatan akan diterima lebih baik. Pendidikan ibu dapat memperbaiki cara penggunaan sumber daya keluarga, sehingga akan berdampak positif terhadap kelangsungan hidup keluarga, salah satunya adalah dalam perawatan ibu hamil. Ibu yang mempunyai pendidikan tinggi lebih sedikit dipengaruhi oleh praktek praktek tradisonal yang merugikan terhadap ibu hamil terutama dalam hal kualitas makanan untuk konsumsi setiap harinya (Nursalam, 2007).

Hubungan Pekerjaan terhadap Kepatuhan Ibu Hamil dalam Mengkonsumsi Tablet Besi (Fe). Hasil penelitan diketahui ibu hamil yang tidak bekerja cenderung tidak patuh dibandingkan ibu yang bekerja. Lingkungan sekitar ibu tinggal berpengaruh dalam hal ini. Ibu hamil yang tinggal di lingkungan tidak bekerja juga pengetahuannya agak sulit berkembang karena untuk memperoleh informasi dan untuk bertukar pendapat terbatas hanya dengan orang-orang itu saja. Pekerjaan merupakan suatu aktivitas sehingga memperoleh penghasilan. Ibu hamil yang mempunyai penghasilan berhubungan dengan kemampuan ibu untuk memperoleh pengetahuan tentang tablet besi dan anemia.

Hubungan Pengetahuan terhadap Kepatuhan Ibu Hamil dalam Mengkonsumsi Tablet Besi (Fe). 


Pengetahuan merupakan
faktor dominan yang sangat
penting untuk terbentuknya
tindakan pada ibu hamil dalam
kepatuhannya mengkonsumsi
tablet besi selama kehamilan.
Perilaku yang didasari
pengetahuan akan lebih baik dari
pada perilaku yang tidak didasari
oleh pengetahuan (Puspasari,
2008).

Tingkat pengetahuan ibu mengenai tablet besi berpengaruh terhadap perilaku untuk patuh dalam mengkonsumsi tablet besi. Ibu hamil yang memiliki pengetahuan mengenai anemia yang cukup baik kemungkinan mendorong ibu untuk lebih patuh mengkonsumsi tablet besi selama kehamilan. Pengetahuan juga dapat diperoleh dari pengalaman langsung ataupun pengalaman orang lain. Pengetahuan dapat diukur dari suatu pendidikan ibu, karena pendidikan yang di miliki ibu hamil rata-rata SMP, maka pengetahuan ibu hamil tentang tablet Fe juga kurang. Dari segi lingkungan juga berpengaruh, ibu yang tinggal di desa mayoritas memiliki penduduk yang pendidikan rendah cenderung memiliki pengetahuan yang terbatas pula. Dari seluruh pertanyaan yang diajukan kepada subjek, sebagian besar subjek tidak mengetahui manfaat atau fungsi zat besi selama kehamilan dan dampak negatif yang ditimbulkan bila tidak mengkonsumsi tablet besi. Jadi tenaga kesehatan perlu melakukan pendekatan kepada ibu hamil untuk meningkatkan pengetahuan ibu hamil dalam mengkonsumsi tablet besi melakukan promosi kesehatan dengan cara pelatihan, seminar, penyuluhan oleh tenaga kesehatan tentang pentingnya mengkonsumsi tablet besi selama kehamilan sehingga bisa meningkatkan kepatuhan ibu hamil dalam mengkonsumsi tablet besi (Fe).

Hubungan Sikap terhadap Kepatuhan Ibu Hamil dalam Mengkonsumsi Tablet Besi (Fe)

Ada beberapa faktor yang mempengaruhi sikap yaitu faktor internal: faktor yang terdapat dalam diri pribadi manusia itu sendri. Faktor ini berupa daya pilih seseorang untuk menerima atau menolak pengaruh dari luar. Faktor eksternal : faktor yang terdapat dari luar manusia itu sendri. Faktor ini berupa interaksi sosial dari kelompok (Wawan, 2011). Sikap disebabkan adanya kemauan dan motivasi, baik itu dari diri sendiri maupun orang lain yang didasari oleh pengetahuan atau pengalaman. Pengalaman bisa didapat ibu hamil secara langsung maupun tidak langsung, sehingga timbul kesadaran untuk bersikap positif atau negatif dalam mengkonsumsi tablet besi. Dari penelitian yang dilakukan menggunakan pertanyaan dari kuesioner didapatkan sebagian besar ibu hamil memiliki sikap 
kurang dalam mengkonsumsi tablet besi.

\section{Hubungan Kepatuhan terhadap Kadar Hemoglobin Ibu Hamil}

Hasil penelitian sebagian besar ibu hamil tidak patuh dalam mengkonsumsi tablet besi. Dari hasil wawancara didapatkan banyak alasan mengapa ibu hamil tidak patuh dalam mengkonsumsi tablet besi selama kehamilan, alasannya antara lain ibu memilih menghentikan konsumsi tablet besi karena bau yang tidak enak dari tablet besi tersebut. Ibu juga mengatakan sering lupa, tidak ada anggota keluarga yang mengingatkan dan malas meminum tablet $\mathrm{Fe}$, takut bayinya lahir terlalu besar, merasa tidak memerlukan vitamin lagi karena sudah merasa sehat. Ibu juga mengabaikan anjuran dari petugas kesehatan tentang jumlah tablet yang harus dikonsumsi selama kehamilan dan mengabaikan cara yang tepat mengkonsumsi tablet Fe. Sebagian ibu hamil memilih mengkonsumsi tablet $\mathrm{Fe}$ bersamaan dengan teh,susu, atau pisang untuk mengurangi bau tidak sedap yang ditimbulkan tablet Fe. $\mathrm{Ibu}$ juga kurang memahami manfaat tablet besi bagi kehamilan.

\footnotetext{
Pengaruh Faktor Predisposisi terhadap Kepatuhan Ibu Hamil dalam Mengkonsumsi Tablet Besi dan Kadar Hemoglobin
}

Faktor pekerjaan dan usia mempunyai nilai odds ratio paling rendah yaitu 0,156 dan 0,675 yang artinya memiliki kekuatan hubungan yang kecil. Sedangkan faktor yang memiliki kekuatan hubungan yang besar adalah pendidikan dan sikap ibu hamil dengan nilai odds ratio 3,867 dan 4,238 , yang artinya ibu hamil yang memiliki pendidikan tinggi dan sikap yang baik mempunyai pengaruh 3,9 dan 4,2 kali lebih patuh dalam mengkonsumsi tablet besi selala kehamilan dibandingkan ibu yang memiliki pendidikan rendah dan sikap yang kurang baik Pada umumnya semakin tinggi pendidikan semakin baik pula pengetahuannya (Hendra, 2008).

\section{Simpulan}

\subsection{Simpulan}

Ada hubungan antara usia, pendidikan, pekerjaan, pengetahuan, sikap, dengan kepatuhan ibu hamil dalam mengkonsumsi tablet besi $(p=$ $0,015 ; 0,01 ; 0,009 ; 0,001 ; 0,03)$. Ada hubungan antara kepatuhan ibu hamil dalam mengkonsumsi tablet besi dengan kadar hemoglobin ibu hamil $(p=0,000)$.

Faktor paling dominan yang mempengaruhi kepatuhan ibu hamil dalam mengkonsumsi tablet besi selama kehamilan adalah sikap ibu hamil dengan nilai odds ratio (OR) 4,238 yang artinya ibu hamil yang memiliki sikap baik mempunyai pengaruh 4,2 kali 
untuk patuh dalam mengkonsumsi tablet besi selama kehamilan dibandingkan ibu hamil yang memiliki sikap yang kurang.

\subsection{Saran}

Untuk peneliti selanjutnya perlu dilakukan penelitian lanjutan, seperti penelitian eksperimen dengan cara pemberian intervensi pada ibu hamil meliputi promosi kesehatan melalui media promosi, melakukan penyuluhan, edukasi, dan motivasi untuk pemantauan kepatuhan ibu hamil dalam mengkonsumsi tablet besi selama kehamilan dalam upaya pencegahan anemia pada ibu hamil.

\section{Daftar Pustaka}

Afriyanti Detty, S. (2012). Hubungan Konsumsi Tablet $\mathrm{Fe}$ dan Pemeriksaan Hemoglobin Terhadap Perdarahan Persalinan. Jurnal Ilmiah Kebidanan STIKes Fort De Kock Bukittinggi, Volume 3 Nomor 1.

Asrina, dkk. (2014). Faktor-faktor yang berhubungan dengan Kejadian Anemia pada Ibu Hamil di Rumah Sakit Ibu dan Anak Siti Fatimah Makasar. Jurnal Ilmiah Kesehatan Diagnosis STIKes Nani Hasanuddin Makassar, Volume 4 Nomor 6.

Hendra, AW. (2008). FaktorFaktor yang Mempengaruhi
Pengetahuan. Tersedia dalam: http://wordpress.com/2008/06/ 07/Konsep_penegtahuan/(diak ses pada tanggal 2 Agustus 2016).

Naga Sholeh, S. (2012). Buku Panduan Lengkap Ilmu Penyakit Dalam. Cetakan pertama. Yogyakarta: Diva Press (Anggota IKAPI).

Nursalam. (2007). Manajemen Keperawatan dan Aplikasinya. Jakarta: Infomedika.

Puspasari Fida, dkk. (2008). Faktor-faktor yang Mempengaruhi Kepatuhan Ibu Hamil Mengkonsumsi Tablet $\mathrm{Fe}$ di Desa Sokaraja Kecamatan Sokaraja Kabupaten Banyumas. Jurnal Keperawatan FKIK Universitas Soedirman (The Soedirman Journal of Nursing), Volume 3 Nomor 1.

Proverawati, A. (2011). Anemia dan Anemia Kehamilan. Cetakan 1. Yogyakarta: Nuha Medika.

Riset Kesehatan dasar. (2013). Prevalensi Anemia. Laporan Badan Penelitian dan Pengembangan Kesehatan. Jakarta: Kementerian Kesehatan RI.

Wawan, Dewi. (2011). Teori dan pengukuran Pengetahuan, Sikap dan Perilaku Manusia. 
ISSN : 2354-5852

e-ISSN : 2579-5783

Yokyakarta: Nulia Medika.

Campbell, Scott and

Fainstein, Susan S. (1996).
Reading in Planning Theory. Cambridge. Blackwell Publishers 